\title{
Побутовий холодильник і його схема заміщення чотириполюсником
}

\author{
Ю. В. Байдак, I. А. Вереітіна, С. А. Коробко
}

Одеська національна академія харчових технологій, вул. Канатна, 112, Одеса, 65039, Україна

Розглянуто схему заміщення побутового холодильника у вигляді еквівалентного активного чотириполюсника, вхідними затискачами якого прийнято випарник, а вихідними - конденсатор. Математичну модель холодильника як чотириполюсника розроблено у вигляді системи двох рівнянь теплового балансу відносно температурного напору і теплового потоку, який трансформується упродовж роботи холодильної машини. Надано визначення режимів неробочого ходу і короткого замикання холодильної машини. Розроблену модель холодильника як чотириполюсника призначено для використання у системах SMART refrigeration.

Ключові слова: Побутовий холодильник; Схема заміщення; Чотириполюсник; Температурний напір; Тепловий потік; Коефіиієнт корисної дї; Коефіиієнт навантаження.

\section{1. Вступ}

Побутовий холодильник (ПХ) розглядається як пристрій, що забезпечує можливість збудження у ньому замкненого процесу зміни агрегатного стану робочого тіла і його течії у одно контурній герметичній системі трубопроводів неоднакового перерізу і об'єму. До складу ПХ входять випарник із джерелами теплового потоку, мотор-компресорний агрегат із втратами електричної енергії у вигляді тепла, приймач теплового потоку - конденсатор, які є поєднані трубопроводами.

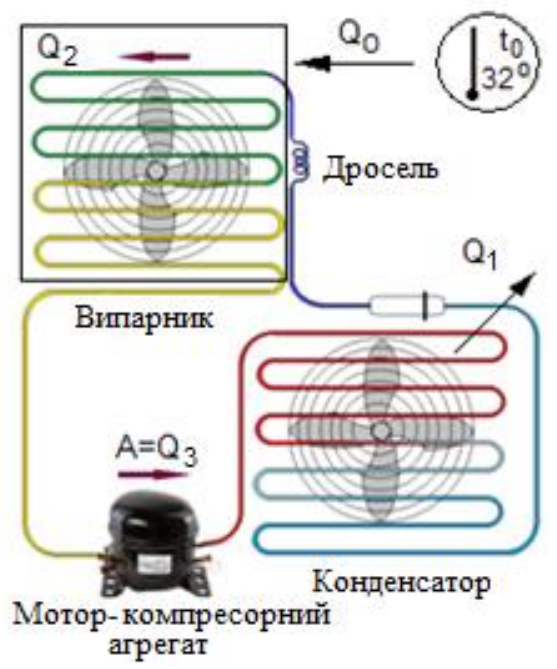

Рисунок 1 - Мнемонічна схема ПХ

Робочим тілом постає речовина, здатна змінювати власний стан (пара, рідина) у залежності від тиску. Зміна фазового стану - випаровування або конденсація забезпечуються за рахунок споживання підведеної із зовні енергії. Пристрій одноконтурної системи ПХ наведено на рисунку 1, в якій компресор забезпечує зростання тиску робочого тіла у приймачі конденсаторі i зменшення у джерелі-випарнику, а також його циркуляцію у замкненому контурі. Конденсатор забезпечує виконання умов фазового переходу робочого тіла 3 газоподібного стану у рідинний. Випарник утворюе умови для кипіння робочого тіла i його охолодження. Дросель-капіляр регулює кількість робочого тіла у випарнику в залежності від перегріву у ньому [1].

\section{2. Теоретичне обгрунтування}

Первинні літературні джерела [1,2], спираючись на діаграму циклу холодильної машини (XМ), розглядають ПХ таким, який складено 3 двох компонентів-випарника і конденсатора, взаємодія між якими встановлюється дроселем та компресором за діаграмою циклу Карно, а саме показниками тиску і ентальпії у чотирьох реперних точках A, B, D,E на рисунку 2.

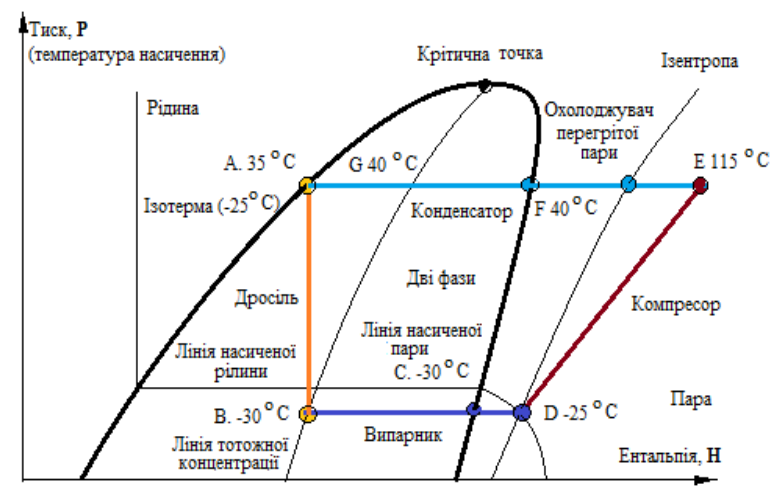

Рисунок 2 - Діаграма тиск-ентальпія

Виходячи 3 цього, ХМ ПХ можна розглядати як чотириполюсник, у якого по два вхідні та вихідні кінці - B i D та D і E відповідно [3]. Вони пов'язані між собою тиском і температурою навколо компресорного агрегату та випарника, як то передбачено умовами випробувань, викладеними у $[4,5,6]$. Вхідними 
величинами щодо розрахунку холодильної продуктивності постають тиск $\boldsymbol{P}$ i температура $\boldsymbol{t}$ на вході і виході випарника та компресора (рисунок 3 ). Відповідно до них, за допомогою діаграми циклу холодильної машини $\boldsymbol{l n} \boldsymbol{P}=\boldsymbol{f}(\boldsymbol{i})$, та такої, яка відповідає типу застосованого хладону, графічно знаходять значення питомих ентальпій $h$ на вході і виході випарника та компресора. За їх значеннями розраховують питому холодильну продуктивність випарника $\boldsymbol{q}_{\mathbf{0}}$, питому роботу стискування компресора i, відповідно до неї, масову витрату хладону $\boldsymbol{G}_{\boldsymbol{a}}$. Холодильна продуктивність, що підлягає визначенню, розраховується як сума добутків значень холодильної продуктивності випарника і масової витрати хладону за весь визначений проміжок часу робочого циклу $\boldsymbol{T}$, тобто як

$$
Q_{2}=\int_{0}^{T} G_{a} q_{0} d \tau
$$

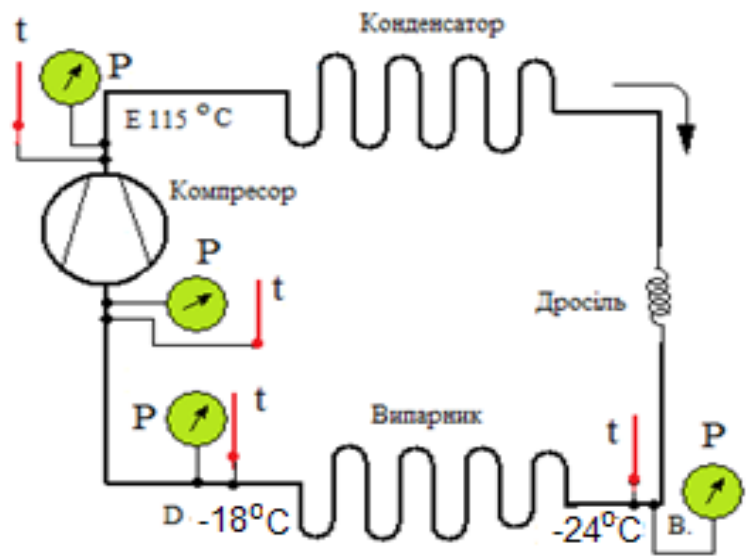

Рисунок 3 - Принципова схема випробувань холодильної продуктивності компресора за спрощеною методикою [6,7]

Метою роботи є заміщення ХМ системою двох рівнянь, що пов'язані такими показниками продуктивності іï ділянок, як тепло і температурний напір у випарнику, мотор-компресорному агрегаті i конденсаторі. При цьому застосовуються аналогії різниці електричних потенціалів $\varphi_{i}-\varphi_{0}$ на ділянці кола (напруги $U_{i 0}$ ) 3 різницею температур $t_{i}-t_{0}$ (температурному напору $\tau_{i 0}$ ), сили електричного струму $I_{i}$ з потоком тепла $Q_{i}$, омічного опору $r$ його тепловим еквівалентом $r_{i}=\frac{1}{k_{T i} F_{i}}$, в яких індекс $i-$ позначка належності до відповідної ділянки або об'єкту: $i=1$ - конденсатор, $i=2$ - випарник, $i=3$ мотор-компресорний агрегат.

\section{3. Схема заміщення XM}

На рисунку 4 наведено схему заміщення ХМ, як активного чотириполюсника де 2'-2" - вхідні затискачі для тепло припливу (випарник), 1'-1" - вихідні затискачі для тепловідводу (конденсатор).

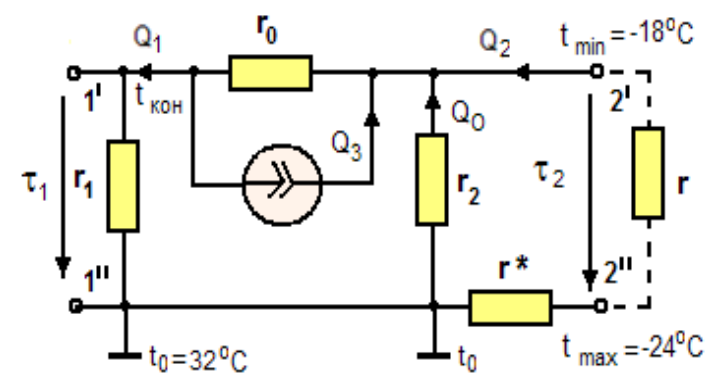

Рисунок 4 - Схема заміщення ХМ чотириполюсником

На схемі виокремлено: $Q_{0}-$ постійний теплоприплив до випарника із оточуючого середовища крізь теплоізоляцію, $Q_{2}$ - тепло, внесене до випарника 3 об'єктом охолодження, $Q_{1}$ - тепло, відведене конденсатором у оточуюче середовище, $Q_{3}$ - тепло від втрат потужності в двигуні мотор-компресорного агрегату; $\tau_{1}$ - температурний напір між конденсатором i оточуючим середовищем; $\tau_{2}$ - температурний напір у випарнику, обумовлений уставкою терморегулятора (гістерезис): $r_{1}=\frac{1}{k_{T 1} F_{1}}-$ тепловий опір між поверхнею конденсатора $F_{1}$ із коефіцієнтом тепловіддачі $k_{T 1}$ i оточуючим середовищем; $r_{2}=\frac{1}{k_{T 2} F_{2}}$ аналогічно для випарника, $r_{3}=\frac{1}{k_{T 3} F_{3}}-$ мотор-компресорного агрегату та $r^{*}=\frac{1}{k_{T *} F_{*}}$, в якому $k_{T *}, F_{*}-$ коефіцієнт тепло припливу до ПХ ззовні і площа його поверхні.

\section{4. Рівняння чотириполюсника}

Відповідно до рівнянь електричної рівноваги, складеним на підставі законів Кірхгофа, їх аналоги теплової рівноваги матимуть вигляд системи залежностей, якими встановлюється зв'язок вихідних величин температурного напору і тепла у конденсаторі з аналогічними до них - вхідними у випарнику

$$
\begin{aligned}
& \tau_{1}=f\left(\tau_{2}, Q_{2}\right), \\
& Q_{1}=f\left(\tau_{2}, Q_{2}\right) .
\end{aligned}
$$

Для започаткованої схеми заміщення на рисунку 4 , ці залежності встановлюються із застосуванням другого та першого законів Кірхгофа наступним чином:

$$
\begin{aligned}
\tau_{1}=r_{0}\left(Q_{2}+Q_{0}\right. & \left.+Q_{3}\right)+\tau_{2}=r_{0} \frac{\tau_{2}}{r_{2}}+\tau_{2}+r_{0}\left(Q_{2}+Q_{3}\right) \\
& =\left(\frac{r_{0}}{r_{2}}+1\right) \tau_{2}+r_{0}\left(Q_{2}+Q_{3}\right) \\
Q_{1} & =\frac{\tau_{1}}{r_{1}}+\left(\frac{\tau_{2}}{r_{2}}+Q_{2}+Q_{3}\right)= \\
& =\left[\left(\frac{r_{0}}{r_{2}}+1\right) \tau_{2}+r_{0}\left(Q_{2}+Q_{3}\right)\right] \frac{1}{r_{1}} \\
& +\left(\frac{\tau_{2}}{r_{2}}+Q_{2}+Q_{3}\right) \\
& =\tau_{2}\left(\frac{1}{r_{1}}+\frac{1}{r_{2}}+\frac{r_{0}}{r_{1} r_{2}}\right) \\
& +\left(\frac{r_{0}}{r_{1}}+1\right)\left(Q_{2}+Q_{3}\right)
\end{aligned}
$$


Враховуючи, що отримані рівняння розглядаються інваріантними для різновидів подібних ПХ, введемо позначення сталих чотириполюсника, а саме:

$$
\begin{array}{cl}
A=\frac{r_{0}}{r_{2}}+1, & B=r_{0}, \\
C=\frac{1}{r_{1}}+\frac{1}{r_{2}}+\frac{r_{0}}{r_{1} r_{2}}, & D=\frac{r_{0}}{r_{1}}+1 .
\end{array}
$$

Відтоді, система рівнянь чотириполюсника перетворюється до виду:

$$
\left\{\begin{array}{l}
\tau_{1}=A \tau_{2}+B\left(Q_{2}+Q_{3}\right) \\
Q_{1}=C \tau_{2}+D\left(Q_{2}+Q_{3}\right)
\end{array}\right.
$$

яким встановлюється зв'язок температурного напору i тепла, що рухається у системі ХМ від входу випарника $\tau_{2}, Q_{2}$ до виходу - конденсатора $\tau_{1}, Q_{1}$ iз урахуванням теплоприпливу від мотор-компресорного агрегату $Q_{3}$.

\section{5. Апробація рівнянь активного чотири полюс- ника}

Апробацію виконано на прикладі ПХ типу КШД260 [8] із розрахунку якого є відомими такі показники як:

- температура зовнішнього середовища $t_{0}=32^{\circ} \mathrm{C}$;

- температура випарника в режимі заморозки $t_{\max }=-24^{\circ} \mathrm{C}$ і відтаювання $t_{\min }=-18^{\circ} \mathrm{C}$;

- холодильна продуктивність

моторкомпресорного агрегату $Q_{3}=93$ Вт. год;

- холодильна продуктивність випарника у режимі заморожування і зберігання об'єктів охолодження $Q_{2}=59$ Вт. год;

- коефіцієнт тепловіддачі та поверхня охолодження конденсатора $\quad k_{T 1} F_{1}=15 \cdot 0,35=$ $5,25 \mathrm{BT} /{ }^{\circ} \mathrm{C}$;

- коефіцієнт тепловіддачі та поверхня охолодження випарника $k_{T 2} F_{2}=12 \cdot 0,35=4,2 \mathrm{Bт} /{ }^{\circ} \mathrm{C}$;

- коефіцієнт тепловіддачі та поверхня охолодження мотор-компресорного агрегату $k_{T 3} F_{3}=$ $10 \cdot 0,25=2,5 \mathrm{BT} /{ }^{\circ} \mathrm{C}$.

Вхідним даним відповідають теплові опори:

- конденсатора $r_{1}=0,19^{\circ} \mathrm{C} / \mathrm{BT}$;

- випарника $r_{2}=0,238^{\circ} \mathrm{C} / \mathrm{BT}$;

- мотор-компресорного агрегату $r_{0}=0,4^{\circ} \mathrm{C} / \mathrm{BT}$, і сталі чотириполюсника за рівняннями (1):

$$
\begin{gathered}
A=\frac{r_{0}}{r_{2}}+1=\frac{0,4}{0,238}+1=2,68 ; \\
B=r_{0}=0,4{ }^{\circ} \mathrm{C} / \mathrm{BT} ; \\
C=\frac{1}{r_{1}}+\frac{1}{r_{2}}+\frac{r_{0}}{r_{1} r_{2}}=\frac{1}{0,19}+\frac{1}{0,238}+\frac{0,4}{0,19 \cdot 0,238}= \\
=18,31 \frac{1}{{ }^{\circ} \mathrm{C} / \mathrm{BT}} ; \\
D=\frac{r_{0}}{r_{1}}+1=\frac{0,4}{0,19}+1=3,105 .
\end{gathered}
$$

Після підстановки у (2), матимемо рівняння активного четирьохполюсника у вигляді

$$
\left\{\begin{array}{c}
\tau_{1}=2,68 \tau_{2}+0,4\left(Q_{2}+Q_{3}\right) \\
Q_{1}=18,31 \tau_{2}+3,105\left(Q_{2}+Q_{3}\right)
\end{array}\right.
$$

Відтак, якщо підставити до нього відомі значення холодильної продуктивності, отримаємо температурний напір конденсатора

$$
\tau_{1}=2,68 \cdot(-6)+0,4 \cdot(59+93)=44,72^{\circ} \mathrm{C},
$$

і його продуктивність

$$
\begin{aligned}
Q_{1}=18,31 & \cdot(-6)+3,105(59+93)= \\
= & 362,1 \mathrm{BT} \cdot \text { год. }
\end{aligned}
$$

За отриманими значеннями продуктивності ХM коефіцієнт корисної дії ПХ становить

$$
\eta=\frac{Q_{1}-\left(Q_{2}+Q_{3}\right)}{Q_{1}}=\frac{362,1-(59+93)}{362,1}=0,58 .
$$

Холодильний коефіцієнт, що вказує на кількість теплоти, яка віднімається від об'єкту охолодження при здійсненні одиниці роботи

$$
\varepsilon=\frac{Q_{2}+Q_{3}}{Q_{1}-\left(Q_{2}+Q_{3}\right)}=\frac{59+93}{362,1-(59+93)}=0,723 .
$$

3 системи рівнянь чотириполюсника витікає, що ХМ працює у робочому режимі, який є проміжним між неробочим ходом та коротким замиканням. Відповідні їм рівняння мають вигляд:

- для неробочого ходу $Q_{2}=0$, якому відповідає відсутність об'єкту охолодження, або його тривале зберігання без відчинення дверей шаф ПХ

$$
\left\{\begin{array}{c}
\tau_{10}=A \tau_{2}+B Q_{3}=-16,8+37,2=20,4^{\circ} \mathrm{C} \\
Q_{10}=C \tau_{2}+D Q_{3}=-109,9+288,8= \\
=178,9 \text { Вт } \cdot \text { год } ;
\end{array}\right.
$$

- для короткого замикання $\tau_{2}=0$, якому відповідає безперервна робота мотор-компресорного агрегату (аварійний випадок)

$$
\left\{\begin{array}{c}
\tau_{1 \kappa}=B\left(Q_{2}+Q_{3}\right)=60,8^{\circ} \mathrm{C} \\
Q_{1 \kappa}=D\left(Q_{2}+Q_{3}\right)=472 \mathrm{BT} \cdot \text { год }
\end{array} .\right.
$$

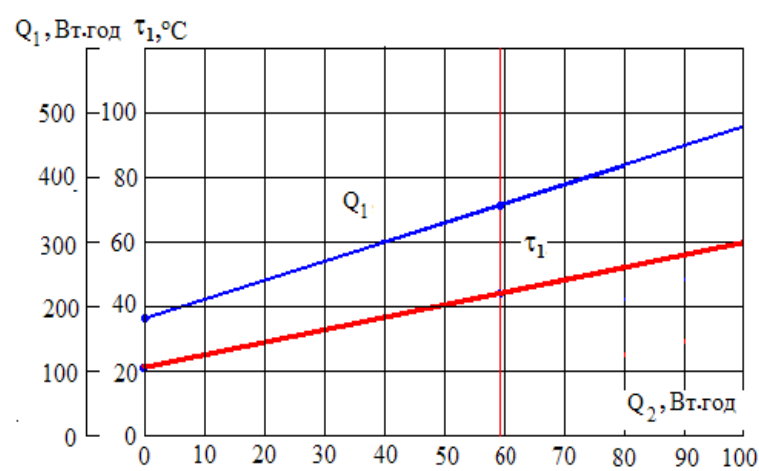

Рисунок 5 - Навантажувальні характеристики ХМ ПХ $\tau_{1}=f\left(Q_{2}\right)$ та $Q_{1}=f\left(Q_{2}\right)$ 
Виходячи з лінійних рівнянь рівноваги ХМ ПХ, можливо побудувати його навантажувальні характеристики $\tau_{1}=f\left(Q_{2}\right)$ та $Q_{1}=f\left(Q_{2}\right)$ в межах режимів неробочого ходу та короткого замикання, які наведено на рисунку 5.

Оптимальний коефіцієнт навантаження ПХ типу КШД-260, що розглядається як приклад, становить:

- за холодильною продуктивністю

$$
\beta_{\text {опт } Q}=\sqrt{\frac{Q_{10}}{Q_{1 \kappa}}}=\sqrt{\frac{178,9}{472}}=0,62 ;
$$

- за температурним напором

$$
\beta_{\text {опт } \tau}=\sqrt{\frac{\tau_{10}}{\tau_{1 \mathrm{\kappa}}}}=\sqrt{\frac{20,4}{60,8}}=0,58 .
$$

Відповідно до них, оптимальний коефіцієнт корисної дії за показником холодильної продуктивності становить

$$
\begin{aligned}
& \eta_{\text {опт } Q}=\frac{Q_{1}-\beta_{\text {опт } Q_{Q}} Q_{2}-Q_{3}}{Q_{1}}=\frac{287-36,58-93}{287} \\
& =0,548, \\
& \text { де } \\
& Q_{1}=18,31 \cdot(-6)+\begin{array}{c}
3,105(59 \cdot 0,62 \cdot+93)=287 \mathrm{BT} \\
\text { год. }
\end{array}
\end{aligned}
$$

Йому відповідає температурний напір конденсатора

$$
\tau_{1}=2,68 \cdot(-6)+0,4 \cdot(59 \cdot 0,58+93)=34,81^{\circ} \mathrm{C} .
$$

\section{Враховуючи}

можливості

рівнянь чотириполюсника, цікавою постає залежність коефіцієнту корисної дії ХМ від навантаження ПХ, тобто $\eta=f\left(\beta_{Q}\right)$

$$
\eta=\frac{Q_{1}-\left(\beta_{Q} Q_{2}+Q_{3}\right)}{Q_{1}}=\frac{C \tau_{2}+(D-1)\left(\beta_{Q} Q_{2}+Q_{3}\right)}{C \tau_{2}+D\left(\beta_{Q} Q_{2}+Q_{3}\right)} .
$$

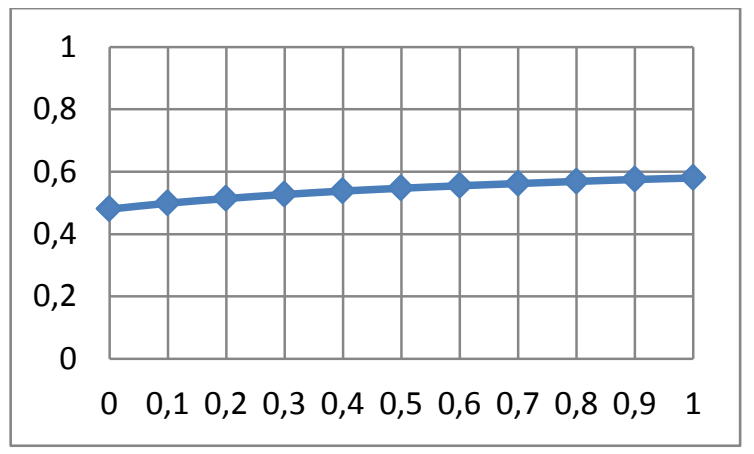

Рисунок 6 - Коефіцієнт корисної дії ХМ у залежності від навантаження випарника

$$
\eta=f\left(\beta_{Q}\right)
$$

Залежність коефіцієнту корисної дії ХМ наведено на рисунку 6, з якої витікає, що у широкому діапазоні зміни завантаження він змінюється в межах $10 \%$. При навантаженні $\beta_{Q}=0$, коефіцієнт корисної дії XМ встановлюється на рівні 0,48 і обумовлений теплоприпливами до ПХ із зовні та від мотор-компресорного агрегату.

\section{Висновки}

1. Вперше розроблено математичну модель ХМ у вигляді системи двох рівнянь, які, у першому наближенні, доцільно застосовувати для аналізу енергетичної ефективності ПХ в цілому.

2. Отримані результати підлягають дискусії і уточненню.

3. Вперше надано обгрунтування крайових режимів роботи ХМ - неробочого ходу та короткого замикання, що дозволяє встановити оптимальне навантаження у випарнику за умов енергетично ефективної роботи ПХ в цілому.

4. Наведені сталі активного чотириполюсника $€$ залежними від теплових опорів, що надає можливість варіювати ними 3 метою спрямованого досягнення показника енергетичної ефективності.

5. Обрана схема заміщення ХМ надає можливість більш коректно підійти до умов i методів експериментального випробування ПХ та зменшити витрати електричної енергії, застосованої на їх проведення.

6. Розроблена математична модель може бути використана при програмуванні мікропроцесорних пристроїв керування роботою інтелектуальної (SMART) побутової техніки для розумного будинку, а саме роботою побутового холодильника в залежності від його завантаження.

\section{Література}

1. Доссат Р. Д. Основы холодильной техники / Под ред. Л. Г. Каплана: Пер. с англ. М. Б. Розенберг. - М.: Легкая и пищевая промышленность, 1984. - 520 с. 2. Диаграмма давление-энтальпия. [электронный ресурс] Дата обращения: 03.10.2018. Режим доступа: http://www.xiron.ru/content/view/30757/173/.

3. Байдак Ю. В. Основи теорії кіл. Навч. посіб. / Юрій Вікторович Байдак. - К.: Вища шк.: Слово, 2009. $271 \mathrm{c}$.

4. EN 28187. Household refrigerating appliances. Refrigerator-freezers. Characteristics and test methods.

5. Бытовые холодильные устройства - холодильники морозильники - характеристики и методы тестирования (ISO 8187: 1991г.); Европейский стандарт EN 28187.

6. Стандарт СЭВ. СТ СЕВ 665-77, Оборудование холодильное. Компрессоры. Методы испытания; Международный стандарт ИСО 917. Компрессоры холодильные. Методы испытаний. Рег. № ИСО 917-74. 7. Исследование и разработка двухкамерного холодильника КШД-260 с низкотемпературной камерой объемом не менее 40 дм $^{3}$, с режимом замораживания продуктов и автоматической оттайкой: Отчет по НИР / Одес. технол. ин-т холод. пром-сти; -№ ГР 15.КО76/80, 5016; Одеса, 1978. - 167 с.

\footnotetext{
Отримана в редакції 05.09.2018, прийнята до друку 04.12.2018
} 


\title{
Household refrigerator and its substitution scheme by two-port network
}

\author{
Yu. V. Baidak, I. A. Vereitina, S. A. Korobko
}

Odessa National Academy of Food Technologies, 112 Kanatnaya str., Odessa, 65039, Ukraine

The substitution scheme for a household refrigerator in the form of an equivalent active two-port network, with an evaporator as the input clamps, and a capacitor as the output ones is considered. The mathematical model of the refrigerator as two-port network is developed as a system of two equations of thermal balance with respect to the temperature difference and heat flow rate, which is transformed during refrigerating machine operation. The definitions of idle speed and short circuit modes with regard to the refrigerator are given. The developed model of the refrigerator as two-port network is intended for use in SMART refrigeration systems.

Keywords: Household Refrigerator; Substitution Scheme; Two-port network; Temperature difference; Heat Flow Rate; Efficiency; Loading Coefficient.

\section{References}

1. Dossat, R. D. (1984) Osnovy kholodilnoy tekhniki / Pod red. L. G. Kaplana: Per. s angl. M. B. Rozenberg. Moskow: Legkaya i pishchevaya promyshlennost, 520 p.

2. Diagramma davleniye - entalpiya. Availible at: http://www.xiron.ru/content/view/30757/173/.

3. Baidak, Yu. V. (2009) Osnovy teorii kil. Navch. posib. / Yurii Viktorovych Baidak. Kyiv: Vyshcha shkola: Slovo, $271 \mathrm{p}$.

4. EN 28187. Household refrigerating appliances. Refrigerator-freezers. Characteristics and test methods. 5. Bytovyie kholodilnyie ustroistva - kholodilniki morozilniki - kharakteristiki i metody testirovania (ISO 8187: 1991g.); Evropeiskii standart EN 28187.
6. Standart SEV. ST SEV 665-77. Oborudovanie kholodilnoie. Kompressory. Metody ispytania; Mezhdunarodnyi standart ISO 917. Kompressory kholodilnyie. Metody ispytanii. Reg. № ISO 917-74.

7. Issledovanie i razrabotka dvukhkamernogo kholodilnika KShD-260 s nizkotemperaturnoi kameroi obiemom ne meneie $40 \mathrm{dm} 3$. s rezhimom zamorazhivania produktov i avtomaticheskoi ottaikoi: Otchet po NIR. Odes. tekhnol. int kholod. prom-sti; No. GR 15.KO76/80. 5016; Odesa, 1978, 167 p. 